\title{
Nota
}

\section{MERCÚRIO EM SOLOS DA REGIÃO SUDESTE DO BRASIL SEM INFLUÊNCIA ANTROPOGÊNICA E SUA CORRELAÇÃO COM AS CARACTERÍSTICAS QUÍMICAS E FÍSICAS}

\author{
Liliane Catone Soares(1)*, Lucília Alves Linhares(2), Fernando Barboza Egreja Filho(3), \\ Cláudia Carvalhinho Windmoller(3) e Maria Irene Yoshida(3)
}

(1) Universidade Federal de Minas Gerais, Instituto de Ciências Exatas, Departamento de Química, Programa de Pós-graduação em Química, Belo Horizonte, Minas Gerais, Brasil.

(2) Universidade Federal de Ouro Preto, Instituto de Ciências Exatas e Aplicadas, Departamento de Ciências Exatas e Aplicadas, João Monlevade, Minas Gerais, Brasil.

(3) Universidade Federal de Minas Gerais, Instituto de Ciências Exatas, Departamento de Química, Belo Horizonte, Minas Gerais, Brasil.

* Autor correspondente.

E-mail: liliane-catone@ufmg.br

\section{RESUMO}

A correlação entre as características físicas e químicas do solo e o teor de mercúrio natural é importante para identificar aquelas que mais influenciam na retenção desse elemento nesses solos e sua distribuição nos diversos compartimentos ambientais. Esse estudo teve por objetivos determinar o teor de $\mathrm{Hg}$ de solos sem influência antropogênica e correlacionar esse teor com as características físicas e químicas dos solos. A relevância deste trabalho se deve ao fato que a maioria das pesquisas é focada em solos contaminados e, em caso de solos tropicais, as pesquisas são ainda mais escassas. As características físicas e químicas de diferentes solos de mata natural do Estado de Minas Gerias e de um solo do Estado do Rio de Janeiro foram correlacionadas com os teores naturais de $\mathrm{Hg}$ dos solos. O teor de $\mathrm{Hg}$ foi determinado empregando-se o analisador direto de Hg DMA-80. A faixa de concentração de $\mathrm{Hg}$ encontrada foi de 0 a $215 \mu \mathrm{g} \mathrm{kg}-1$ com média de $81 \mu \mathrm{g} \mathrm{kg}-1$. $\mathrm{O}$ teor de $\mathrm{Hg}$ dos solos correlacionou-se principalmente com o teor de argila e o pH do solo. Não houve correlação entre o teor de $\mathrm{Hg}$ e o de C. Para solos com teores mais altos de $\mathrm{Hg}$ e mesma textura, a capacidade de troca catiônica passa a ser uma variável importante.

Palavras-chave: metal pesado, solos tropicais, $\mathrm{pH}$, textura. 


\title{
ABSTRACT: MERCURY CONTENT IN SOILS OF SOUTHEASTERN BRAZIL WITHOUT ANTHROPOGENIC INFLUENCE AND ITS CORRELATION WITH SOIL CHARACTERISTICS
}

\begin{abstract}
Correlation between physical and chemical characteristics of soils and their natural mercury content is important for identifying the parameters that most influence Hg retention in these soils and its distribution in different environmental compartments. The aim of this study was to quantify the $\mathrm{Hg}$ content of tropical soils without anthropogenic influence and correlate it with physical and chemical soil characteristics. The present study is relevant because most research focuses on contaminated soils and, in the case of tropical soils, research is even more limited. Therefore, different soils from natural forests of southeastern Brazil were characterized and the results of chemical and physical characterization were correlated with soil Hg content. Mercury content was determined through the direct Hg analyzer DMA-80. Mercury concentrations in soils were between 0 and $215 \mu \mathrm{kg}^{-1}$ and the average was $81 \mu \mathrm{g} \mathrm{kg-1}$. Soil $\mathrm{Hg}$ content correlated mainly with the clay content and soil $\mathrm{pH}$. There was no correlation between Hg content and $C$ content. For soils with higher levels of $\mathrm{Hg}$ and the same texture, cation exchange capacity becomes an important variable.
\end{abstract}

Keywords: heavy metal, tropical soils, pH, texture.

\section{INTRODUÇÃO}

O conhecimento das concentrações consideradas naturais de metais em solos é fundamental para que se possa avaliar adequadamente o grau de contaminação de áreas impactadas. No Brasil, assim como na Indonésia, na Colômbia e em alguns outros países da América do Sul, Ásia e África, as minerações artesanais e de pequena escala de ouro são a maior fonte de emissão de mercúrio (Hg) (UNEP, 2008). Segundo o anuário mineral de 2010 do Departamento Nacional de Produção Mineral (DNPM, 2010), das $2.592 \mathrm{t}$ de reservas lavráveis de ouro do Brasil, 582 t (22\% do total) estão localizadas no Estado de Minas Gerais; assim, justifica-se a importância de estudar os teores de $\mathrm{Hg}$ nos solos desse Estado.

$\mathrm{Na}$ maioria das pesquisas realizadas sobre determinação de $\mathrm{Hg}$ em solos em diferentes regiões ao redor do mundo, foram estudadas áreas impactadas por atividades antropogênicas, principalmente mineração de $\mathrm{Hg}$ (Gosar et al., 2006; García-Sanchez et al., 2009; Malferrari et al., 2011), mineração de Au (Varejão et al., 2009; Cesar et al., 2011; Swenson et al., 2011) e indústria de cloro-soda (Biester et al., 2002; Grangeon et al., 2012). Entretanto, estudos sobre teores de $\mathrm{Hg}$ em solos não contaminados, principalmente em solos de regiões tropicais, são menos numerosos. No Brasil, isso é particularmente importante porque ainda existe a dificuldade de se definirem os valores de referência para solos contaminados, justamente em razão da variabilidade dos teores naturais consequente da heterogênea geoquímica dos solos (Mello e Abrahão, 2013). Apesar da variabilidade dos solos, tanto os estudos sobre áreas não contaminadas quanto sobre áreas impactadas concentram-se predominantemente na região da Amazônia brasileira, seguidos, em menor extensão, da região do Quadrilátero Ferrífero em Minas Gerais.

Estudos feitos em áreas não impactadas da Amazônia brasileira revelam uma variada faixa de concentrações de $\mathrm{Hg}$, valores superiores aos teores obtidos em muitos dos estudos realizados em outras regiões do mundo (Quadro 1). No que se diz respeito ao Estado de Minas Gerais, algumas pesquisas foram realizadas nas regiões do Quadrilátero Ferrífero e da bacia do rio Doce (Quadro 1); e a grande maioria foi no sentido de avaliar o impacto ocasionado pelas minerações de $\mathrm{Au}$.

Além das contribuições antrópicas, os teores naturais de $\mathrm{Hg}$ dos solos do Estado de Minas Gerais são muito variáveis $\left(20 \mathrm{a} 4.330 \mu \mathrm{g} \mathrm{kg}^{-1}\right)$. Essa enorme variabilidade foi verificada pelo grupo coordenado pela Fundação Estadual do Meio Ambiente, que definiu os valores de referência de qualidade para os teores de metais pesados nos solos mineiros (Mello e Abrahão, 2013). Os resultados revelaram altíssimas concentrações naturais de $\mathrm{Hg}$ em solos do Quadrilátero Ferrífero, chegando a $4.330 \mu \mathrm{g} \mathrm{kg}^{-1}$, que é muito superior ao valor de referência de qualidade (VRQ) para $\mathrm{Hg}$ em solos (50 $\mu \mathrm{g} \mathrm{kg}^{-1}$, COPAM, 2011) e chega a ser 8,66 vezes superior ao limite de prevenção de $\mathrm{Hg}$ (500 $\mu \mathrm{g} \mathrm{kg}^{-1}$, COPAM, 2011).

Tendo em vista que os dados de concentrações de $\mathrm{Hg}$ nos solos brasileiros encontrados na literatura são de algumas áreas específicas, geralmente impactadas por garimpo de ouro, este estudo teve por objetivos determinar o teor de $\mathrm{Hg}$ de solos em áreas sem aporte antropogênico evidente do metal, predominantemente de Minas Gerais, e correlacionar esse teor com as características físicas e químicas dos solos. Espera-se contribuir para o 
Quadro 1. Variação dos teores de mercúrio na Amazônia brasileira, em várias regiões do Estado de Minas Gerais (Brasil) e no mundo

\begin{tabular}{lc}
\hline Local & Teor de Hg \\
\hline & $\mu \mathrm{g} \mathrm{kg} \mathbf{H}^{-1}$ \\
Amazônia brasileira & $<25-6760$ \\
Manaus (Valle et al., 2005) & $245-439$ \\
Vale do rio Madeira (Lechler et al., 2000) & $90-210$ \\
Vale do rio Tapajós (Roulet et al., 1998) & \\
Regiões do Estado de Minas Gerais & $90-1230$ \\
Estação ecológica do Tripuí (Palmieri et al., 2006) & $40-1100$ \\
Mariana e Ouro Preto (Windmoller et al., 2007) & $179,3-690,1$ \\
Sub-bacia do rio Carmo, bacia do rio Doce & \\
(Varejão et al., 2009) & $20-4330$ \\
Todo o Estado de Minas Gerais (Mello e & \\
Abrahão, 2013) & \\
Mundo & $22-9400$ \\
Beijing (Chen et al., 2010) & 400 \\
Espanha (Pérez-Sirvent et al., 2009) & $30-4190$ \\
Bélgica (Tack et al., 2005) & $<10-60$ \\
Estados Unidos (Ericksen et al., 2006) & \\
\hline
\end{tabular}

aumento do banco de dados sobre teores naturais de $\mathrm{Hg}$ em solos do Sudeste brasileiro e da relação desses teores com as características dos solos, a fim de subsidiarem estudos sobre o comportamento de $\mathrm{Hg}$ nesses e em solos semelhantes.

\section{MATERIAL E MÉTODOS}

Amostras de diferentes classes de solos (Quadro 2) foram coletadas em várias cidades do Estado de Minas Gerais e em uma cidade do Estado do Rio de Janeiro, em áreas de mata natural, não impactadas por atividades agrícolas e industriais. Foram coletadas amostras de 14 classes solos em duas profundidades (horizontes A e B), exceto três deles, os quais apenas um dos horizontes foi analisado, totalizando, portanto, 25 amostras.

As amostras foram secas ao ar, desagregadas e passadas em peneira de $2 \mathrm{~mm}$ (TFSA). Nessas amostras, foi realizada a análise textural. Para caracterização química e quantificação de $\mathrm{Hg}$, as amostras foram ainda trituradas e passadas em peneira de 0,177 $\mathrm{mm}$ (80 mesh).

As determinações de $\mathrm{pH}$ em água, a capacidade de troca catiônica (CTC) e a análise granulométrica foram realizadas de acordo com Claessen (1997). $\mathrm{O}$ teor de $\mathrm{C}$ foi determinado pelo método de Walkley-Black (Jackson, 1958). Determinaram-se os teores de $\mathrm{Fe}$ e de $\mathrm{Al}$ extraíveis por soluções de ditionito-citrato-bicarbonato (DCB) e soluções de oxalato ácido de amônio, de acordo com Mehra e Jackson (1960) e McKeague e Day (1966), respectivamente. Os teores de $\mathrm{Fe}$ e $\mathrm{Al}$ (o último que se supõe fazer parte da estrutura dos óxidos de Fe, como substituinte isomórfico) foram quantificados empregando-se espectrometria de absorção atômica (espectrômetro da Perkin Elmer, modelo Analyst 200). Todos os reagentes utilizados no trabalho foram de grau analítico e todas as análises foram efetuadas em triplicatas.

A análise mineralógica da fração argila foi efetuada por difratometria de raios-X (DRX). Tratamentos químicos, como desferrificação com $\mathrm{DCB}$, adição de $\mathrm{KCl}, \mathrm{MgCl}_{2} /$ glicerol e tratamentos térmicos (aquecimento a $550{ }^{\circ} \mathrm{C}$ ) foram efetuados nas amostras para auxiliar a interpretação dos difratogramas, de acordo com Resende et al. (2005). Todas as lâminas de argila analisadas foram montadas por esfregaço (lâminas orientadas). Os difratogramas foram obtidos empregando-se um goniômetro Rigaku Geigerflex, provido de um monocromador de grafite e tubo de cobre, usando radiação $\mathrm{Ka}$ do $\mathrm{Cu}(\Lambda=1,5418 \mathrm{~A})$. A velocidade de varredura utilizada foi de $4^{\circ} 2 \theta \mathrm{min}^{-1}$ e constante de tempo de um segundo para cada amostra.

A quantificação total de $\mathrm{Hg}$ foi realizada, em triplicata, com massas exatas de amostra (em torno de 0,1000 g), empregando-se o analisador direto de Hg DMA-80 (Direct Mercury Analyzer) da Milestone. Nesse equipamento, o $\mathrm{Hg}$ é quantificado por absorção atômica em 253,65 $\mathrm{nm}$. Antes da determinação do $\mathrm{Hg}$ nas amostras, efetuou-se a análise dos materiais de referência Montana Soil Nist-2711 $\left(6,25 \pm 0,19 \mathrm{\mu g} \mathrm{g}^{-1}\right)$ e River Sediment GBW-GBW 08301 RCV $8221\left(0,220 \pm 0,040 \mu \mathrm{g} \mathrm{g}^{-1}\right)$ no DMA-80. Uma vez que os resultados situaram-se dentro dos valores certificados, considerou-se o método exato e adequado para as análises.

Fez-se uma análise de especiação do Hg nos solos, empregando-se a técnica de termodessorção/absorção atômica (TDAAS), utilizando-se um sistema de termodessorção acoplado a um espectrômetro de absorção atômica GBC 932 AA (São Paulo, Brasil). O sistema de termodessorção foi constituído por um tubo de quartzo envolto por uma bobina de $\mathrm{Ni}-\mathrm{Cr}$ e um material isolante conectado por um termopar a um controlador de temperatura (aquecimento até $600{ }^{\circ} \mathrm{C}$ numa taxa de aquecimento de $33{ }^{\circ} \mathrm{C} \mathrm{min}{ }^{-1}$ ) e nitrogênio como gás de arraste, na vazão de $200 \mathrm{~mL} \mathrm{~min}{ }^{-1}$. O sinal de absorvância foi registrado em função da temperatura do forno, e os termogramas gerados foram interpretados segundo Valle et al. (2005).

Foram realizadas a análise de componentes principais (PCA) e a análise de agrupamento (HCA) entre as características físicas e químicas e teor de $\mathrm{Hg}$ de todos os solos, empregando-se o programa Matlab R2009b. Para o HCA, os dados foram escalados; foi empregado o método de Ward 
Quadro 2. Classe de solo, horizontes, profundidade, classificação de acordo com o Sistema Brasileiro de Classificação de Solo e localização dos solos estudados

\begin{tabular}{|c|c|c|c|c|c|c|}
\hline Solo & Classificação(1) & Hor. & Prof. & Cidade de coleta & Coordenadas & Material de origem \\
\hline & & & $\mathrm{cm}$ & & & \\
\hline PVA & Argissolo Vermelho-Amarelo distrófico típico & A & $0-24$ & Viçosa & $\begin{array}{l}\text { S } 20^{\circ} 45^{\prime} 14^{\prime \prime} \\
\text { W } 42^{\circ} 52^{\prime} 55^{\prime \prime}\end{array}$ & $\begin{array}{l}\text { Sedimentos aluviais } \\
\text { estratificados }\end{array}$ \\
\hline LVA & Latossolo Vermelho-Amarelo distrófico típico & $\mathrm{B}$ & $20-200$ & Ponte Nova & $\begin{array}{l}\text { S } 20^{\circ} 24^{\prime} 59^{\prime \prime} \\
\text { W } 42^{\circ} 54^{\prime} 31^{\prime \prime}\end{array}$ & Gnaisse \\
\hline \multirow[t]{2}{*}{$\mathrm{LVd}$} & \multirow[t]{2}{*}{ Latossolo Vermelho distrófico típico } & A & $0-24$ & \multirow{2}{*}{$\begin{array}{l}\text { Conselheiro } \\
\text { Lafaiete }\end{array}$} & \multirow{2}{*}{$\begin{array}{l}\text { S } 20^{\circ} 39^{\prime} 37^{\prime \prime} \\
\text { W } 43^{\circ} 47^{\prime} 10^{\prime \prime}\end{array}$} & \multirow[t]{2}{*}{ Calcário } \\
\hline & & $\mathrm{B}$ & $27-86$ & & & \\
\hline \multirow[t]{2}{*}{$\operatorname{LVAd}_{1}$} & \multirow{2}{*}{$\begin{array}{l}\text { Latossolo Vermelho-Amarelo distrófico } \\
\text { húmico }\end{array}$} & A & $0-21$ & \multirow[t]{2}{*}{ Barbacena } & \multirow{2}{*}{$\begin{array}{l}\mathrm{S} 21^{\circ} 13^{\prime} 33^{\prime} \\
\mathrm{W} 43^{\circ} 46^{\prime} 25^{\prime \prime}\end{array}$} & \multirow[t]{2}{*}{ Gnaisse } \\
\hline & & $\mathrm{B}$ & $21-200$ & & & \\
\hline \multirow[t]{2}{*}{$\mathrm{LVj}$} & \multirow{2}{*}{ Latossolo Vermelho perférrico húmico } & A & $0-37$ & \multirow[t]{2}{*}{ Nova Lima } & \multirow{2}{*}{$\begin{array}{l}\mathrm{S} 19^{\circ} 59^{\prime} 08^{\prime \prime} \\
\mathrm{W} 43^{\circ} 50^{\prime} 48^{\prime \prime}\end{array}$} & \multirow[t]{2}{*}{ Itabiritos } \\
\hline & & $\mathrm{B}$ & $37-140$ & & & \\
\hline \multirow[t]{2}{*}{ NVef } & \multirow[t]{2}{*}{ Nitossolo Vermelho eutrófico típico } & A & $0-30$ & \multirow[t]{2}{*}{ Guiricema } & \multirow{2}{*}{$\begin{array}{l}\mathrm{S} 21^{\circ} 00^{\prime} 28^{\prime \prime} \\
\mathrm{W} 42^{\circ} 43^{\prime} 04^{\prime \prime}\end{array}$} & \multirow[t]{2}{*}{ Basalto } \\
\hline & & $\mathrm{B}$ & $30-200$ & & & \\
\hline \multirow[t]{2}{*}{$\mathrm{TCp}$} & \multirow[t]{2}{*}{ Luvissolo Crômico Pálico abrúptico } & A & $0-25$ & \multirow[t]{2}{*}{ Itaperuna } & \multirow{2}{*}{$\begin{array}{l}\mathrm{S} 21^{\circ} 12^{\prime} 18^{\prime \prime} \\
\mathrm{W} 41^{\circ} 53^{\prime} 16^{\prime \prime}\end{array}$} & \multirow{2}{*}{$\begin{array}{l}\text { Charnockitos/Enderbitos e } \\
\text { Granulitos }\end{array}$} \\
\hline & & B & $25-200$ & & & \\
\hline \multirow[t]{2}{*}{ CXbe } & \multirow[t]{2}{*}{ Cambissolo Háplico Tb eutrófico latossólico } & A & $0-38$ & \multirow[t]{2}{*}{ Pedro Leopoldo } & \multirow{2}{*}{$\begin{array}{l}\mathrm{S} 19^{\circ} 37^{\prime} 05^{\prime \prime} \\
\mathrm{W} 44^{\circ} 02^{\prime} 35^{\prime \prime}\end{array}$} & \multirow[t]{2}{*}{ Calcário } \\
\hline & & $\mathrm{B}$ & $38-200$ & & & \\
\hline CXbd & Cambissolo Háplico Tb distrófico típico & B & $20-110$ & Mariana & $\begin{array}{l}\text { S } 20^{\circ} 22^{\prime} 16^{\prime \prime} \\
\text { W } 43^{\circ} 16^{\prime} 21^{\prime \prime}\end{array}$ & $\begin{array}{c}\text { Micaxisto com } \\
\text { influência de quartzitos }\end{array}$ \\
\hline $\mathrm{FFcd}_{1}$ & Plintossolo Pétrico concrecionário distrófico & A & $0-20$ & Brasilândia de & $\mathrm{S} 17^{\circ} 04^{\prime} 53^{\prime \prime}$ & Coberturas terciárias e \\
\hline & & $\mathrm{B}$ & $20-50$ & & W $46^{\circ} 00^{\prime} 16^{\prime \prime}$ & $\begin{array}{l}\text { quartenarias associadas } \\
\text { a rochas pelíticas (siltitos }\end{array}$ \\
\hline $\mathrm{FFcd}_{2}$ & Plintossolo Pétrico concrecionário distrófico & A & $0-20$ & & $\mathrm{~S} 17^{\circ} 05^{\prime} 16^{\prime \prime}$ & $\begin{array}{l}\text { e ardósias) do grupo } \\
\text { Bambuí com possível }\end{array}$ \\
\hline & & $\mathrm{B}$ & $20-50$ & & W $45^{\circ} 59^{\prime} 12^{\prime \prime}$ & $\begin{array}{l}\text { contribuição do Arenito } \\
\text { Urucuia }\end{array}$ \\
\hline CXd & Cambissolo Háplico distrófico & A & $0-20$ & & $\mathrm{~S} 17^{\circ} 04^{\prime} 59^{\prime \prime}$ & \\
\hline & & $\mathrm{B}$ & $20-50$ & & $\mathrm{~W} 46^{\circ} 00^{\prime} 05^{\prime \prime}$ & \\
\hline Rqo & Neossolo Quartzarênico órtico latossólico & $\mathrm{A}$ & $0-20$ & João Pinheiro & $\begin{array}{l}\text { S } 17^{\circ} 25^{\prime} 48^{\prime \prime} \\
\text { W } 46^{\circ} 04^{\prime} 36^{\prime \prime}\end{array}$ & $\begin{array}{l}\text { Coberturas terciárias e } \\
\text { quartenárias associadas } \\
\text { ao arenito urucuia }\end{array}$ \\
\hline & & B & $20-50$ & & & \\
\hline $\operatorname{LVAd}_{2}$ & Latossolo Vermelho-Amarelo distrófico & A & $0-20$ & & $\begin{array}{l}\mathrm{S} 17^{\circ} 47^{\prime} 50^{\prime \prime} \\
\mathrm{W} 46^{\circ} 08^{\prime} 05^{\prime \prime}\end{array}$ & \\
\hline & & $\mathrm{B}$ & $20-50$ & & & \\
\hline
\end{tabular}

(1) Segundo Santos et al. (2006).

e distância de Mahalanobis. No entanto, essas análises de agrupamento não se evidenciaram frutíferas para correlacionar os teores de $\mathrm{Hg}$ com as características dos solos e acabaram agrupando os solos em razão das similaridades entre quaisquer das variáveis estudadas, o que não é útil para este estudo (ver resultados). Sendo assim, buscando encontrar similaridades entre as características dos solos ou região de origem das amostras que pudesse influenciar na retenção do $\mathrm{Hg}$, o conjunto total foi dividido em cinco classes arbitrárias com faixas de amplitude de $50 \mu \mathrm{g} \mathrm{kg}^{-1}$ : inferior a 50, 50-100, 100-150, 150-200 e 200-250 $\mathrm{\mu g} \mathrm{kg}^{-1}$. Estabeleceu-se a faixa de amplitude de $50 \mu \mathrm{g} \mathrm{kg}^{-1}$ para que o primeiro grupo pudesse abranger os solos com teor de $\mathrm{Hg}$ dentro do valor de referência de qualidade (VRQ), e que os demais abrangessem solos com teores de $\mathrm{Hg}$ que fossem múltiplos do VRQ.

Realizaram-se correlações entre os teores de $\mathrm{Hg}$ e as características químicas e físicas dos solos estudados, a fim de avaliar as principais variáveis que influenciam na concentração do $\mathrm{Hg}$ no solo. As análises de correlação de Pearson foram efetuadas utilizando-se o programa Statistica 8.0, e os coeficientes de correlação foram testados pelo teste t, com $95 \%$ de probabilidade. As análises de correlação foram feitas para os seguintes grupos de amostras: conjunto de todas as amostras; amostras que apresentavam diferença significativa entre os teores de $\mathrm{Hg}$ dos horizontes $\mathrm{A}$ e $\mathrm{B}$ de um 
mesmo solo, comparadas pelo teste $t$ com $95 \%$ de confiança, segundo Miller e Miller (1993). Nesse momento, foram consideradas apenas as amostras que constituíam horizonte A e B de um mesmo solo, totalizando, portanto, 22 amostras; e amostras com teores de $\mathrm{Hg}$ acima de $50 \mathrm{\mu g} \mathrm{kg}^{-1}$, que corresponde ao VRQ.

\section{RESULTADOS E DISCUSSÃO}

Os resultados da caracterização dos solos estudados encontram-se no quadro 3 . No texto e nas figuras, sempre que necessário, a letra A ou B após a abreviatura da classificação do solo designa o horizonte, por exemplo: NVef-A significa Nitossolo Vermelho eutrófico típico horizonte A.

Todas as amostras analisadas evidenciaram teores de $\mathrm{Hg}$ abaixo do limite de prevenção de $500 \mu \mathrm{g} \mathrm{kg}^{-1}$ (COPAM, 2011), para solos, com teor médio de $81 \mathrm{\mu g} \mathrm{kg}^{-1}$ (Figura 1). No entanto, essa média é superior às médias de alguns países (Quadro 1) e, inclusive, superior ao Valor de Referência de Qualidade para o Estado de Minas Gerais, de $50 \mathrm{\mu g} \mathrm{kg}^{-1}$ (COPAM, 2011). Ainda assim, os valores determinados estão dentro das faixas encontradas por outros estudos realizados nesse Estado (Quadro 1) e de algumas regiões da Amazônia (Quadro 1).

Quadro 3. Características químicas e físicas dos solos

\begin{tabular}{|c|c|c|c|c|c|c|c|c|c|c|c|c|}
\hline \multirow[t]{2}{*}{ Solo(1) } & \multirow[t]{2}{*}{ Hor. } & \multirow[t]{2}{*}{$\mathrm{pH}\left(\mathrm{H}_{2} \mathrm{O}\right)$} & \multirow[t]{2}{*}{ CTC(2) } & \multirow[t]{2}{*}{ Argila } & \multirow[t]{2}{*}{ Silte } & \multirow[t]{2}{*}{ Areia } & \multirow[t]{2}{*}{ Textura } & \multirow[t]{2}{*}{$\mathrm{C}$} & \multicolumn{2}{|c|}{$\mathrm{Fe}_{2} \mathrm{O}_{3}$} & \multicolumn{2}{|c|}{$\mathrm{Al}_{2} \mathrm{O}_{3}$} \\
\hline & & & & & & & & & $\operatorname{DCB}^{(3)}$ & Oxalato(4) $^{(4)}$ & $\operatorname{DCB}^{(5)}$ & Oxalato(6) $^{(6)}$ \\
\hline \multirow[b]{2}{*}{ PVA } & \multirow[b]{2}{*}{ A } & \multirow[b]{2}{*}{5,10} & \multirow{2}{*}{$\begin{array}{c}\mathrm{cmol}_{\mathrm{c}} \mathrm{kg}-1 \\
4,50\end{array}$} & \multicolumn{3}{|c|}{$\mathrm{g} \mathrm{kg}^{-1}$} & \multirow[b]{2}{*}{ Argilosa } & \multirow{2}{*}{$\begin{array}{c}\% \\
1,607\end{array}$} & \multicolumn{4}{|c|}{$\mathrm{g} \mathrm{kg}^{-1}$} \\
\hline & & & & 436,3 & 211,7 & 342,0 & & & 116,13 & 3,01 & 3,24 & 2,75 \\
\hline LVA & B & 5,27 & 5,18 & 659,1 & 86,5 & 254,4 & Argilosa & 1,328 & 83,60 & 0,44 & 15,95 & 1,63 \\
\hline \multirow[t]{2}{*}{$\mathrm{LVd}$} & $\mathrm{A}$ & 4,98 & 3,09 & 454,5 & 127,2 & 418,3 & Argilosa & 3,436 & 182,94 & 2,51 & 17,20 & 10,44 \\
\hline & B & 5,10 & 2,35 & 633,3 & 239,4 & 127,3 & Argilosa & 1,781 & 155,84 & 2,54 & 31,52 & 3,83 \\
\hline \multirow[t]{2}{*}{$\operatorname{LVAd}_{1}$} & A & 5,24 & 2,16 & 551,8 & 208,7 & 239,5 & Argilosa & 2,087 & 31,65 & 2,66 & 6,93 & 7,68 \\
\hline & B & 6,22 & 4,17 & 484,5 & 174,6 & 340,9 & Argilosa & 2,059 & 33,04 & 0,71 & 0,00 & 1,62 \\
\hline \multirow[t]{2}{*}{$\mathrm{LVj}$} & A & 5,31 & 4,78 & 216,0 & 414,2 & 369,8 & Média & 2,164 & 428,81 & 7,83 & 102,60 & 7,83 \\
\hline & B & 5,81 & 6,45 & 250,3 & 431,5 & 318,2 & Média & 1,882 & 454,96 & 8,17 & 123,00 & 3,27 \\
\hline \multirow[t]{2}{*}{ NVef } & A & 6,17 & 7,98 & 413,9 & 217,6 & 368,4 & Argilosa & 1,791 & 90,18 & 2,65 & 11,11 & 2,76 \\
\hline & B & 5,44 & 9,56 & 542,4 & 404,7 & 53,0 & Argilosa & 1,119 & 181,06 & 5,70 & 19,94 & 2,55 \\
\hline \multirow[t]{2}{*}{ TCp } & A & 6,13 & 6,29 & 418,1 & 244,3 & 337,6 & Argilosa & 1,364 & 72,12 & 1,10 & 5,18 & 1,34 \\
\hline & $\mathrm{B}$ & 6,10 & 5,81 & 619,5 & 199,2 & 181,3 & Argilosa & 1,051 & 79,82 & 1,14 & 7,06 & 1,03 \\
\hline \multirow[t]{2}{*}{ CXbe } & $\mathrm{A}$ & 7,52 & 12,19 & 524,4 & 380,6 & 95,0 & Argilosa & 2,526 & 68,62 & 1,73 & 13,43 & 13,11 \\
\hline & B & 6,91 & 5,52 & 703,5 & 209,4 & 87,1 & Argilosa & 0,783 & 64,09 & 1,08 & 10,11 & 2,49 \\
\hline CXbd & B & 5,20 & 1,58 & 185,2 & 129,5 & 685,3 & Arenosa & 0,565 & 5,56 & 1,62 & 5,07 & 2,72 \\
\hline \multirow[t]{2}{*}{$\mathrm{FFcd}_{1}$} & $\mathrm{~A}$ & 5,45 & 6,56 & 114,2 & 318,2 & 567,7 & Média & 1,490 & 23,15 & 1,48 & 3,73 & 0,96 \\
\hline & B & 4,88 & 2,42 & 221,7 & 315,3 & 463,1 & Média & 1,078 & 23,05 & 0,47 & 0,00 & 0,91 \\
\hline \multirow[t]{2}{*}{$\mathrm{FFcd}_{2}$} & $\mathrm{~A}$ & 5,61 & 3,36 & 147,1 & 521,1 & 331,8 & Média & 1,312 & 18,10 & 1,04 & 3,65 & 0,89 \\
\hline & B & 4,30 & 2,32 & 193,2 & 297,7 & 509,1 & Média & 0,946 & 24,65 & 0,36 & 0,00 & 0,73 \\
\hline \multirow[t]{2}{*}{ CXd } & A & 5,66 & 7,13 & 193,4 & 315,8 & 490,1 & Média & 3,036 & 55,11 & 2,09 & 6,20 & 1,66 \\
\hline & B & 5,05 & 2,94 & 285,6 & 225,2 & 410,8 & Média & 1,546 & 36,76 & 1,10 & 0,00 & 1,38 \\
\hline \multirow[t]{2}{*}{ RQo } & A & 4,49 & 1,30 & 110,1 & 36,9 & 853,0 & Arenosa & 0,907 & 2,73 & 0,20 & 0,92 & 0,73 \\
\hline & B & 4,71 & 1,12 & 148,5 & 29,8 & 821,8 & Arenosa & 0,506 & 2,17 & 0,18 & 0,71 & 0,48 \\
\hline $\mathrm{LVAd}_{2}$ & $\mathrm{~A}$ & 5,40 & 7,59 & 338,1 & 107,5 & 554,4 & Média & 2,712 & 48,33 & 1,51 & 17,07 & 6,50 \\
\hline & B & 4,61 & 7,71 & 472,7 & 78,5 & 454,6 & Argilosa & 1,152 & 62,29 & 0,75 & 18,05 & 1,13 \\
\hline
\end{tabular}

(1) PVA: Argissolo Vermelho-Amarelo distrófico típico; LVA: Latossolo Vermelho-Amarelo distrófico típico; LVd: Latossolo Vermelho distrófico típico; LVAd $_{1}$ : Latossolo Vermelho-Amarelo distrófico húmico; LVj: Latossolo Vermelho Perférrico húmico; NVef : Nitossolo Vermelho eutrófico típico; TCp: Luvissolo Crômico Pálico abrúptico; CXbe: Cambissolo Háplico Tb eutrófico latossólico; CXbd: Cambissolo Háplico Tb distrófico típico; $\mathrm{FFcd}_{1}, \mathrm{FFcd}_{2}$ : Plintossolo Pétrico concrecionário distrófico; CXd: Cambissolo Háplico distrófico; RQo: Neossolo Quartzarênico órtico latossólico; $\mathrm{LVAd}_{2}$ : Latossolo Vermelho-Amarelo distrófico. (2) Capacidade de Troca Catiônica. (3) Ferro extraído com citrato-ditionito-bicarbonato. (4) Ferro extraído com oxalato ácido de amônio. (5) Alumínio extraído com citrato-ditionitobicarbonato. (6) Alumínio extraído com oxalato ácido de amônio. 


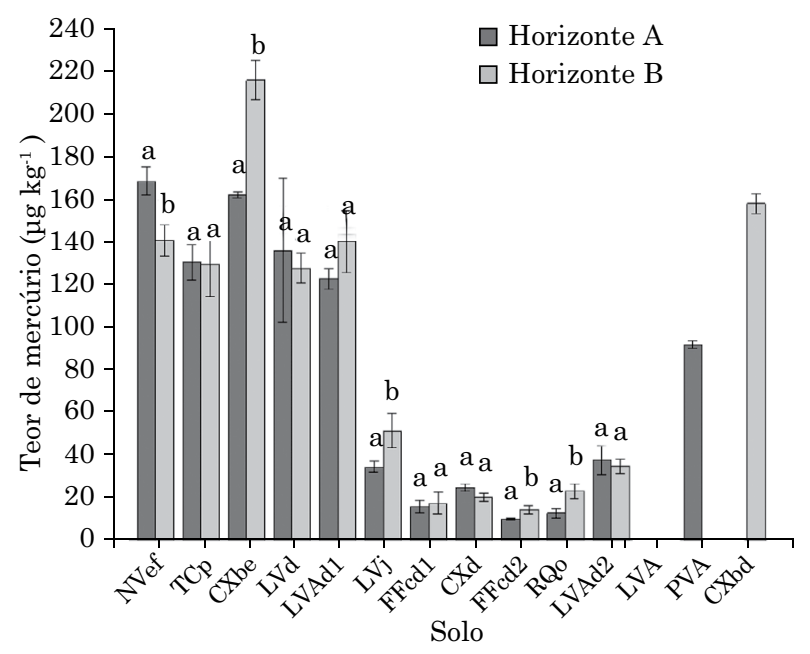

Figura 1. Teor de mercúrio total natural das amostras. As linhas representam os desvios-padrões da triplicata. Barras com a mesma letra para um mesmo tipo de solo indicam que não há diferença significativa entre os teores de mercúrio dos horizontes $\mathrm{A}$ e B (teste t, p<0,05). Para os solos LVA, CXbd e PVA foi analisado apenas um dos horizontes. Para o solo LVA, o teor de mercúrio médio é $1 \times 10^{-4} \mathrm{\mu g} \mathrm{kg}^{-1}$ com desvio-padrão igual a zero.

A maioria dos termogramas gerados pelas análises por TDAAS apresentou picos muito discretos ou ausência de picos por causa dos baixos teores de $\mathrm{Hg}$ nos solos. Todavia, para todos os termogramas onde foi possível observar a presença de pico, esse apareceu na região característica do $\mathrm{Hg}^{2+}$, entre 250 e $400^{\circ} \mathrm{C}$, segundo Valle et al. (2005), como o termograma do horizonte B do solo CXbe, com maior teor de Hg (Figura 2). Nesse termograma, aparecem dois picos claros de termodessorção, sendo um maior em $291^{\circ} \mathrm{C}$ e um de menor intensidade em $368^{\circ} \mathrm{C}$. Embora ambos sejam atribuídos a $\mathrm{Hg}^{2+}$, os dois picos caracterizam diferentes sítios de adsorção ou diferentes compostos de $\mathrm{Hg}^{2+}$.

O histograma da distribuição de frequência dos 25 solos, de acordo com as cinco classes de teor de $\mathrm{Hg}$ (Figura 3) evidencia que para $48 \%$ das amostras (RQo-A; RQo-B; FFcd 1 -A; FFcd 1 -B; FFcd 2 -A; FFcd $_{2}$-B; CXd-A; CXd-B; LVA-B; LVAd 2 -A; LVAd 2 -B; e LVj-A), o teor de $\mathrm{Hg}$ ficou abaixo do VRQ, com média de $21 \mathrm{\mu g} \mathrm{kg}^{-1}$. Dessas, nove são oriundas do Planalto Central, dos municípios de João Pinheiro e Brasilândia. As demais são dos municípios de Nova Lima e Ponte Nova.

Entre os solos que apresentaram teores de $\mathrm{Hg}$ abaixo do VRQ, e que se encontra o teor de $\mathrm{Hg}$ no material de origem descrito na literatura, estão os derivados de arenito (RQo-A; RQo-B, $\mathrm{LVAd}_{2}$-A e $\mathrm{LVAd}_{2}$-B), rocha que apresenta entre 1 e $18 \mu \mathrm{g} \mathrm{kg}^{-1} \mathrm{de} \mathrm{Hg}$ (McNeal e Rose, 1974). Mesmo

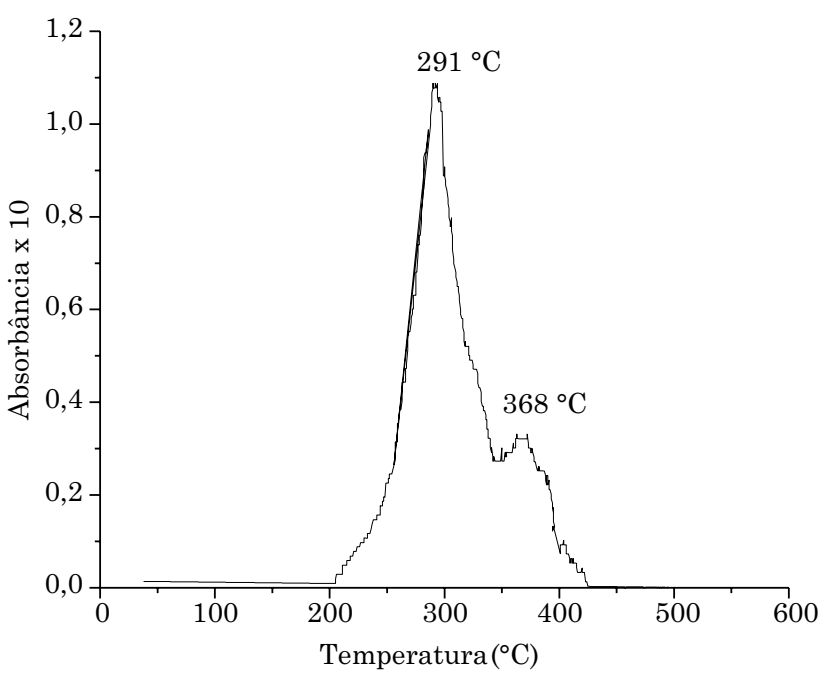

Figura 2. Termograma do solo CXbe (Cambissolo Háplico Tb eutrófico latossólico), horizonte B.

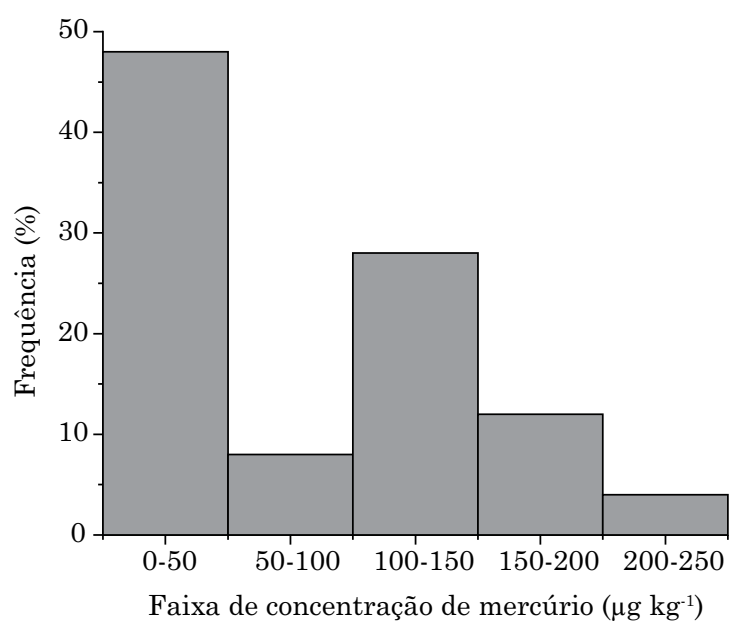

Figura 3. Distribuição de frequência dos 25 solos de acordo com classes de teores com amplitude de 50 pg kg-1.

derivados de material com baixos teores de $\mathrm{Hg}$, esses solos apresentaram maiores teores de $\mathrm{Hg}$ que o arenito (13,1 $\mathrm{\mu g} \mathrm{kg}^{-1}$, para o RQo-A; $23,7 \mathrm{\mu g} \mathrm{kg}^{-1}$, para o RQo-B; 37,9 $\mathrm{g} \mathrm{kg} \mathrm{k}^{-1}$, para o LVAd ${ }_{2}$-A; e

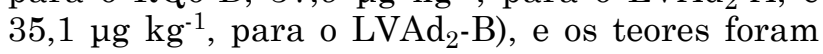
maiores nas amostras com maiores teores de argila, possivelmente pela adsorção do $\mathrm{Hg}$ nos minerais da fração argila.

Duas amostras demonstraram teores de $\mathrm{Hg}$ entre 50 e $100 \mathrm{hg} \mathrm{kg}^{-1}$ (LVj-B e PVA-A), sete amostras apresentaram teores de $\mathrm{Hg}$ entre $100 \mathrm{e}$ $150 \mu \mathrm{g} \mathrm{kg}^{-1}\left(\operatorname{LVAd}_{1}-\mathrm{A}, \mathrm{LVAd}_{1}-\mathrm{B}, \mathrm{LVd}-\mathrm{A}, \mathrm{LVd}-\mathrm{B}\right.$, TCp-A, TCp-B e NVef-B), três entre 150 e $200 \mu \mathrm{g} \mathrm{kg}^{-1}$ (NVef-A, CXbd-B e CXbe-A) e apenas uma acima de $200 \mathrm{\mu g} \mathrm{kg}^{-1}$ (CXbe-B). Dentre as amostras com teores mais altos de $\mathrm{Hg}$, encontram-se os solos eutróficos 
avermelhados NVef e CXbe originários de basalto e calcário, respectivamente.

De maneira geral, os teores de $\mathrm{Hg}$ encontrados nos solos estão acima das faixas encontradas na literatura para os teores do metal nos respectivos materiais litológicos de origem, o que pode significar que no processo pedogenético o $\mathrm{Hg}$ se concentra, diferentemente dos cátions mais móveis. É claro que não se pode excluir, mesmo para solos de mata nativa, a contribuição de $\mathrm{Hg}$ atmosférico que pode ser transportado de fontes poluidoras distantes (Wang et al., 2003; Hissler e Probst, 2006; Guédron et al., 2013; González-Fernández et al., 2014).

Solos derivados de calcário, rocha cujos teores de $\mathrm{Hg}$ situam-se entre 4 e $14 \mathrm{\mu g} \mathrm{kg}^{-1}$ (McNeal e Rose, 1974) e $18 \mathrm{\mu g} \mathrm{kg}^{-1}$ (Agostino et al., 2014), apresentaram-se entre os com teores mais elevados deste estudo, chegando a $215,6 \mathrm{\mu g} \mathrm{kg}^{-1}$ para o solo CXbe-B. Os solos CXbe-A e CXbe-B foram os que apresentaram os maiores valores de $\mathrm{pH}, 7,52$ e 6,91, respectivamente. Pode-se esperar que o elevado $\mathrm{pH}$ de abrasão da rocha calcária tenha favorecido a concentração do $\mathrm{Hg}$ liberado no intemperismo, por processos de adsorção e precipitação. Contudo, mesmo no solo LVd, que apresenta valor de $\mathrm{pH}$ em torno de 5 , a elevação dos teores de $\mathrm{Hg}$, em relação aos da rocha calcária, se deu de forma importante. Essas amostras, em particular, são as que apresentam os segundos maiores teores de Fe extraídos por DCB, que deve ser a fase mais importante de retenção do $\mathrm{Hg}$ nesses solos, por processos de adsorção específica, como observado por Roulet e Lucotte (1995) e Roulet et al. (1998). Essa associação forte do $\mathrm{Hg}$ nos solos avermelhados, com maiores teores de óxidos de Fe, pode ser observada também para os solos NVef-A e NVef-B, cujos teores determinados de $\mathrm{Hg}\left(168,3\right.$ e $140,6 \mu \mathrm{g} \mathrm{kg}{ }^{-1}$, respectivamente) foram bem superiores às faixas de concentração de $\mathrm{Hg}$ relatadas em basalto $\left(4 \mathrm{a} 31 \mathrm{\mu g} \mathrm{kg}^{-1}\right.$, segundo Srivastava (1979); e 5 a $9 \mu \mathrm{kg}^{-1}$, segundo Hall e Pelchat (1997). Uma exceção a essa expectativa de elevados teores de óxidos de $\mathrm{Fe}$ e grandes fatores de concentração de $\mathrm{Hg}$ se verificou para os solos LVj-A (34,7 $\mu \mathrm{g} \mathrm{kg}^{-1}$ de Hg) e LVj-B (51,7 $\mathrm{ug} \mathrm{kg}^{-1}$ de $\mathrm{Hg}$ ), que são os que evidenciaram os maiores teores de $\mathrm{Fe}$ e $\mathrm{Al}$ extraídos pelo $\mathrm{DCB}$ e pelo oxalato e não apresentaram teores de $\mathrm{Hg}$ tão mais elevados que os da rocha de origem, itabirito (5 a $25 \mathrm{\mu g} \mathrm{kg}^{-1}$, segundo Cabral et al. (2008). Além disso, esse solo situa-se dentro do Quadrilátero Ferrífero, região que chega a apresentar teores de $\mathrm{Hg}$ quase 10 vezes maiores que o VRQ desse metal. E mesmo que o solo tenha sido coletado em uma região preservada de atividades antrópicas, o $\mathrm{Hg}$ proveniente das minas de ouro de regiões adjacentes pode se depositar nesses solos. Esses baixos teores de $\mathrm{Hg}$ dos solos de Nova Lima $(\mathrm{LVj})$ podem estar associados ao fato de o Latossolo Perférrico apresentar baixos teores de argila, mineralogia dominada por hematita primária, oriunda do itabirito e quartzo, de tamanho grosseiro e baixa capacidade adsortiva. Portanto, ainda que o $\mathrm{Hg}$ tenha sido liberado pelo intemperismo ou proveniente de outras fontes, não houve condições propícias para o Hg concentrar-se no solo.

Nos solos derivados de gnaisse, rocha cujos teores

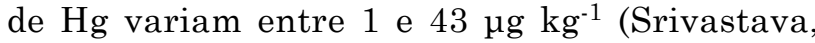
1979), também não se observou uma relação direta com os teores de $\mathrm{Hg}$ encontrados nas rochas do embasamento cristalino e os teores de $\mathrm{Hg}$ nos solos supostamente originados dessas rochas. Nesse caso, comparando-se dois Latossolos Vermelho-Amarelos, derivados de gnaisse, verificaram-se teores elevados de $\mathrm{Hg}$ no solo de Barbacena (122,7 $\mathrm{\mu g} \mathrm{kg}^{-1}$, para o LVAd $_{1}$-A; e 140,3 $\mathrm{\mu g} \mathrm{kg}^{-1}$, para o $\mathrm{LVAd}_{1}$-B) em contraste com o solo LVA-B, de Ponte Nova, que apresentou apenas $0,0001 \mu \mathrm{g} \mathrm{kg}^{-1} \mathrm{de} \mathrm{Hg}$ total. De fato, o processo de concentração de elementos no solo não pode ser decorrente apenas do material de origem. Grimaldi et al. (2008) estudando solos da Guiana Francesa (Oxisol e Ultisol) determinaram que o teor de $\mathrm{Hg}$ no perfil dos solos estudados foi mais fortemente influenciado pelo $\mathrm{Hg}$ atmosférico do que pelo $\mathrm{Hg}$ litogênico.

Atuando juntamente com a contribuição litológica e o aporte atmosférico de $\mathrm{Hg}$, as características dos solos devem ser determinantes para a concentração de $\mathrm{Hg}$ nesses solos. $\mathrm{O} \mathrm{pH}$, a CTC, o teor de argila (McBride, 1994), os teores de óxidos cristalinos e amorfos de $\mathrm{Fe}$ e $\mathrm{Al}$ (Roulet et al., 1998), o teor e a qualidade da matéria orgânica (McBride, 1994; Ravichandran, 2004) desses solos favorecem a manutenção de metais, após a sua liberação pelo intemperismo das rochas matrizes. De fato, nas amostras de Nitossolo (NVef, horizontes A e B) e de Cambissolo eutrófico (CXbe, horizontes A e B), observaram-se todos esses aspectos conjugados (Quadro 4) e, inclusive, maior concentração de $\mathrm{Hg}$ nos horizontes $\mathrm{A}$, com percentagens de $\mathrm{C}$ superiores aos dos horizontes B dos solos. Nos casos onde não há grandes diferenças entre os teores de $\mathrm{Hg}$ dos horizontes $\mathrm{A}$ e $\mathrm{B}$, com maiores teores no horizonte $\mathrm{B}$, é possível que o $\mathrm{Hg}$ proveniente de outras fontes, ou no próprio mineral original pouco interferido pelo intemperismo, tenha sido mobilizado para o horizonte $\mathrm{B}$.

$\mathrm{O}$ teor de $\mathrm{Hg}$ natural dos solos apresenta correlação significativa positiva apenas com o $\mathrm{pH}$ $(r=0,64)$ e com o teor de argila $(r=0,62)$ e correlação significativa e negativa com o teor de areia $(r=-0,53)$ (Quadro 4). Apesar de haver tendência de elevação do teor de $\mathrm{Hg}$ com o aumento do valor do $\mathrm{pH}$, não existem valores de $\mathrm{pH}$ que determinam o início e final das faixas de concentrações escolhidas. Esse comportamento é explicado quando se realiza uma análise de correlação somente entre as amostras de mesmo horizonte. Para este estudo, foram retirados os três solos que apresentavam apenas um horizonte (embora no estudo com todos os solos, a presença das três amostras não altere significativamente a matriz 
Quadro 4. Coeficientes de correlação de Pearson entre as características físicas e químicas dos solos

\begin{tabular}{|c|c|c|c|c|c|c|c|c|c|c|c|}
\hline & $\mathbf{H g}$ & $\mathrm{pH}\left(\mathrm{H}_{2} \mathrm{O}\right)$ & CTC & Argila & Silte & Areia & C & $\mathbf{F e}_{\text {DCB }}$ & $\mathbf{F e}_{\mathrm{Ox}}$ & $\mathrm{Al}_{\mathrm{DCB}}$ & $\mathrm{Al}_{\mathrm{Ox}}$ \\
\hline $\mathrm{Hg}(1)$ & 1,00 & & & & & & & & & & \\
\hline $\mathrm{pH}\left(\mathrm{H}_{2} \mathrm{O}\right)^{(2)}$ & $0,64^{*}$ & 1,00 & & & & & & & & & \\
\hline CTC(3) & 0,27 & $0,64^{*}$ & 1,00 & & & & & & & & \\
\hline Argila(4) & $0,62^{*}$ & $0,44^{*}$ & 0,33 & 1,00 & & & & & & & \\
\hline Silte ${ }^{(4)}$ & $-0,03$ & 0,34 & 0,33 & $-0,17$ & 1,00 & & & & & & \\
\hline $\operatorname{Areia}^{(4)}$ & $-0,53^{*}$ & $-0,60^{*}$ & $-0,49^{*}$ & $-0,79^{*}$ & $-0,47^{*}$ & 1,00 & & & & & \\
\hline $\mathrm{C}^{(5)}$ & 0,05 & 0,31 & 0,35 & $-0,12$ & 0,39 & $-0,12$ & 1,00 & & & & \\
\hline $\mathrm{Fe}_{\mathrm{DCB}}{ }^{(6)}$ & 0,03 & 0,09 & 0,22 & 0,06 & $0,43^{*}$ & $-0,32$ & 0,39 & 1,00 & & & \\
\hline $\mathrm{Fe}_{\mathrm{Ox}}(7)$ & 0,10 & 0,11 & 0,28 & $-0,01$ & $0,54^{*}$ & $-0,32$ & $0,42^{*}$ & $0,92^{*}$ & 1,00 & & \\
\hline $\mathrm{Al}_{\mathrm{DCB}^{(8)}}$ & $-0,09$ & 0,07 & 0,18 & $-0,05$ & $0,41^{*}$ & $-0,19$ & 0,39 & $0,95^{*}$ & $0,87^{*}$ & 1,00 & \\
\hline $\mathrm{Al}_{\mathrm{Ox}}{ }^{(9)}$ & 0,35 & 0,35 & 0,32 & 0,27 & 0,14 & $-0,32$ & $0,62^{*}$ & 0,34 & 0,35 & 0,29 & 1,00 \\
\hline
\end{tabular}

*Correlação significativa com 95 \% de confiança pelo teste t. (1) Teor de mercúrio. (2) pH em água. (3) Capacidade de Troca Catiônica. (4) Teor. (5) Porcentagem de carbono. (6) Ferro extraído com citrato-ditionito-bicarbonato. (7) Ferro extraído com oxalato ácido de amônio. (8) Alumínio extraído com citrato-ditionito-bicarbonato. (9) Alumínio extraído com oxalato ácido de amônio.

de coeficientes de correlação). A correlação entre o teor de $\mathrm{Hg}$ e o $\mathrm{pH}$ do solo aumenta para o conjunto de amostras de horizonte $\mathrm{B}(\mathrm{r}=0,84)$ e deixa de ser significativa para o conjunto de amostras de horizonte $\mathrm{A}(\mathrm{r}=0,56)$ (matrizes de correlação não apresentadas neste trabalho), o que demonstra que a correlação entre o $\mathrm{pH}$ e o teor de $\mathrm{Hg}$ do conjunto total de amostras é promovida principalmente pelos horizontes B dos solos. Esse comportamento se justifica pela presença de maior número de variáveis que contribui para a retenção do $\mathrm{Hg}$ no horizonte A, destacando-se a presença de matéria orgânica que exerce grande influência na retenção de $\mathrm{Hg}$. Todavia, a retenção de $\mathrm{Hg}$ pela matéria orgânica é determinada pelo tipo de matéria orgânica presente no horizonte superficial e não simplesmente pelo teor total dela, em razão de grupos SH de altíssima afinidade pelo metal (Ravichandran, 2004). Essa variabilidade condicionada a maior número de fatores justifica a diminuição da correlação entre $\mathrm{pH}$ e teor de $\mathrm{Hg}$ quando apenas amostras de horizonte A são analisadas.

A correlação positiva do teor de $\mathrm{Hg}$ total natural com o pH pode estar relacionada com fatores pedológicos ou químicos. Solos com valores de $\mathrm{pH}$ mais elevados podem apresentar menores graus de intemperismo quando comparados aos de mesma origem, em processo de intemperismo mais avançado (McBride, 1994). Portanto, podem preservar minerais que contribuem com maiores teores de $\mathrm{Hg}$, sem que esse tenha sido liberado pelo intemperismo do solo. Além disso, mesmo que o processo de intemperismo tenha disponibilizado $\mathrm{Hg}$ para a solução do solo, em ambientes mais alcalinos, a sua mobilidade será menor e existirá uma tendência de concentrar o Hg por adsorção específica nos óxidos e na matéria orgânica (McBride, 1994; Brown et al., 1995), na adsorção não específica, nas cargas do solo (Sposito, 2008), ou, ainda, na precipitação (Brown et al., 1995). No caso do $\mathrm{Hg}$, sua precipitação ocorre principalmente por causa da hidrólise do cátion mercúrico. $\mathrm{O} \mathrm{Hg}$ se hidrolisa em faixa de $\mathrm{pH}$ de 2 a 6 , dependendo da concentração do íon mercúrico (Fergusson, 1990), portanto, uma vez que o $\mathrm{pH}$ dos solos está entre 4 e 8 , a hidrólise do íon mercúrico é provável na solução de todos os solos estudados.

Em relação ao teor de argila, quando se realiza uma análise de correlação somente entre as amostras de mesmo horizonte, a correlação com o teor de $\mathrm{Hg}$ aumenta para 0,89 para ambos os conjuntos de amostras (matrizes de correlação não apresentadas neste trabalho), evidenciando a importância da argila na retenção de $\mathrm{Hg}$ independentemente do horizonte. A argila é importante porque os íons metálicos tendem a ficar retidos nas frações mais finas do solo, visto que a fração argila é a fração mais reativa em razão da sua alta superfície específica e da presença de minerais secundários, óxidos de $\mathrm{Fe}$ e Al cristalinos ou amorfos.

De maneira geral, a maior parte dos solos investigados apresentou mineralogia da fração argila simples e típica de solos oxídicos. Todas as amostras evidenciaram caulinita como componente principal da mineralogia da fração argila, sendo esse predomínio mais expressivo no Argissolo Vermelho-Amarelo (PVA) e nos Latossolos Vermelho-Amarelos, onde apareceram como picos bem pronunciados indicando grandes quantidades de caulinita. No entanto, os Plintossolos $\left(\mathrm{FFcd}_{1} \mathrm{e}\right.$ $\mathrm{FFcd}_{2}$ ) foram os que apresentaram os picos menos intensos de caulinita entre os solos estudados. Dentre os óxidos de Fe, identificaram-se a goethita e hematita em praticamente todos os solos e a gibbsita em grande parte das amostras dos Latossolos, Argissolo e Plintossolos. Em nenhuma das amostras constataram-se quantidades significativas de minerais $2: 1$ expansíveis. 
Segundo a correlação de Pearson, os parâmetros $\mathrm{pH}$ e teor de argila parecem ser os mais importantes para a concentração de $\mathrm{Hg}$ no solo e quando atuam simultaneamente favorecem ainda mais a adsorção de $\mathrm{Hg}$, pois o solo com o maior teor de $\mathrm{Hg}$ (CXBe-B) é justamente aquele com o maior teor de argila. Em contrapartida, o solo com menor teor de $\mathrm{Hg}$ (LVA-B) apresenta o segundo maior teor de argila; ou seja, o teor de argila exclusivamente não determina a concentração de $\mathrm{Hg}$ no solo; certamente, outros fatores devem ser considerados e o $\mathrm{pH}$ é fundamental; por exemplo, o solo CXBe, horizonte B, apresenta caráter neutro $(\mathrm{pH}=6,91)$ enquanto o LVA-B, caráter ácido $(\mathrm{pH}=5,27)$. De fato, o solo com maior $\mathrm{pH}(\mathrm{CXBe}-\mathrm{A}, \mathrm{pH}=7,52)$ demonstra uma das maiores concentrações de $\mathrm{Hg}$ e teor de argila.

$\mathrm{O}$ gráfico biplot foi gerado a partir da análise de componentes principais (PCA) (Figura 4). A primeira componente explica apenas cerca de $40 \%$ da variância dos dados, e seriam necessárias seis componentes para explicar pelo menos $90 \%$. Analisando-se o gráfico, verificou-se que não há nenhuma separação evidente dos dados, exceto pelas amostras LVj-A e LVj-B, que são separadas por apresentarem teor de óxidos de Fe muito elevado; e as amostras RQo-A e RQo-B, que são separadas por serem solos arenosos. Isso acontece porque a maioria absoluta das amostras apresenta textura argilosa. Quando se faz uma análise de componentes principais, apenas entre as amostras argilosas (gráfico não mostrado neste trabalho), não se observa nenhuma separação. De toda maneira, embora não haja separação significativa das amostras, é possível observar no gráfico da figura 4 tendência de agrupamento das amostras com teores mais altos de $\mathrm{Hg}$ (quadrante com valores positivos de $\mathrm{PC} 1$ e negativos de $\mathrm{PC} 2$ ) em razão do $\mathrm{pH}$, teor de argila e CTC. A análise de HCA não indicou a influência de uma variável predominante na concentração de $\mathrm{Hg}$, que está relacionado simultaneamente com diversas outras variáveis (Figura 5a). Dessa forma, os solos foram agrupados por causa das similaridades de suas características físicas, principalmente textura (Figura 5b).

$\mathrm{O}$ teor de $\mathrm{Hg}$ não apresentou correlação significativa com a porcentagem de C orgânico. A falta de correlação entre essas duas características também foi observada por Wasserman et al. (2007), estudando solos de fazendas da Amazônia sem histórico de garimpo, mesmo para os pesquisados da Amazônia que apresentaram porcentagem de $\mathrm{C}$ bem superiores aos dos estudados neste trabalho. Ao contrário do observado para solos de regiões temperadas e boreais, não há acumulação de $\mathrm{Hg}$ associada com matéria orgânica em solos ferralíticos (Roulet e Lucotte, 1995; Roulet et al., 1998). Ravichandran (2004) discute esse comportamento para sistemas aquáticos e explica que a falta de correlação entre os dois parâmetros

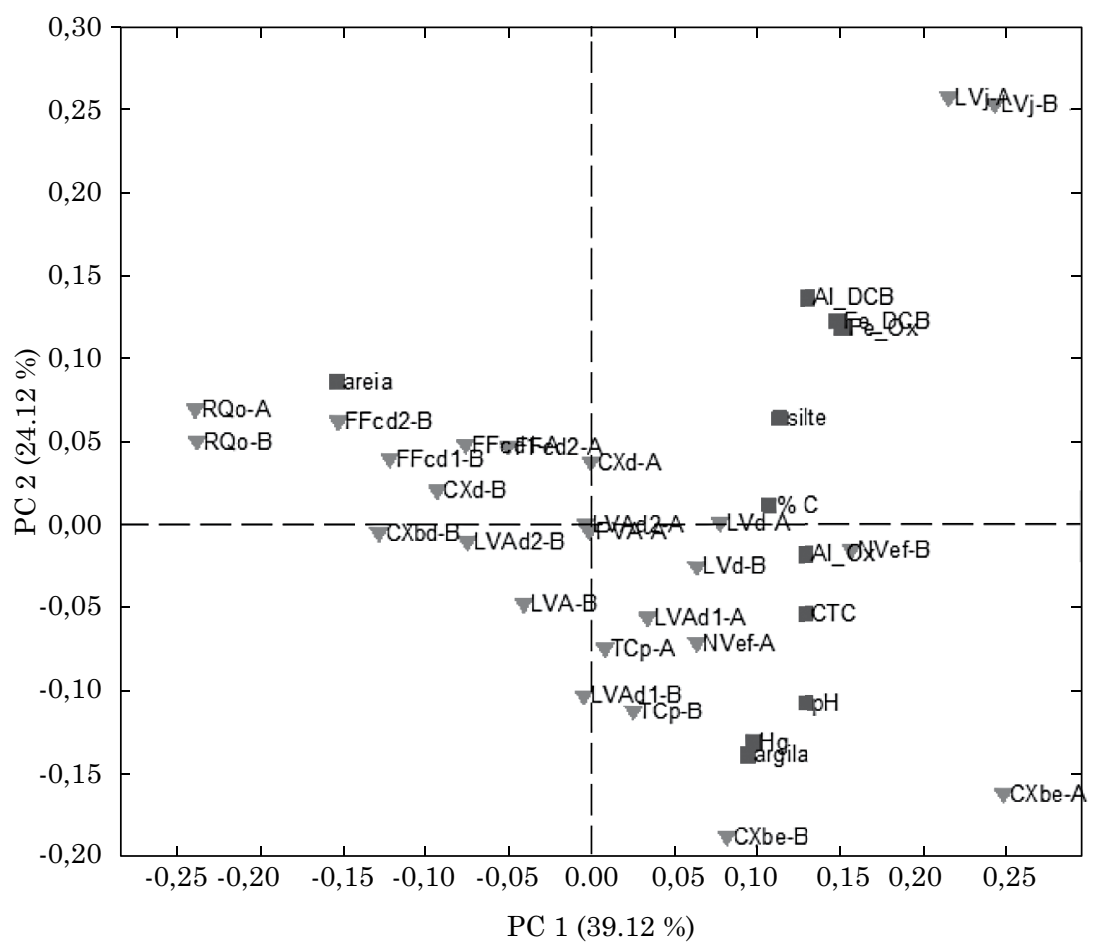

Figura 4. Gráfico biplot da primeira componente principal (PC1) versus a segunda componente principal (PC2) para análise de componentes principais (PCA) considerando-se todas as características físicas e químicas das amostras estudadas. 
(a)

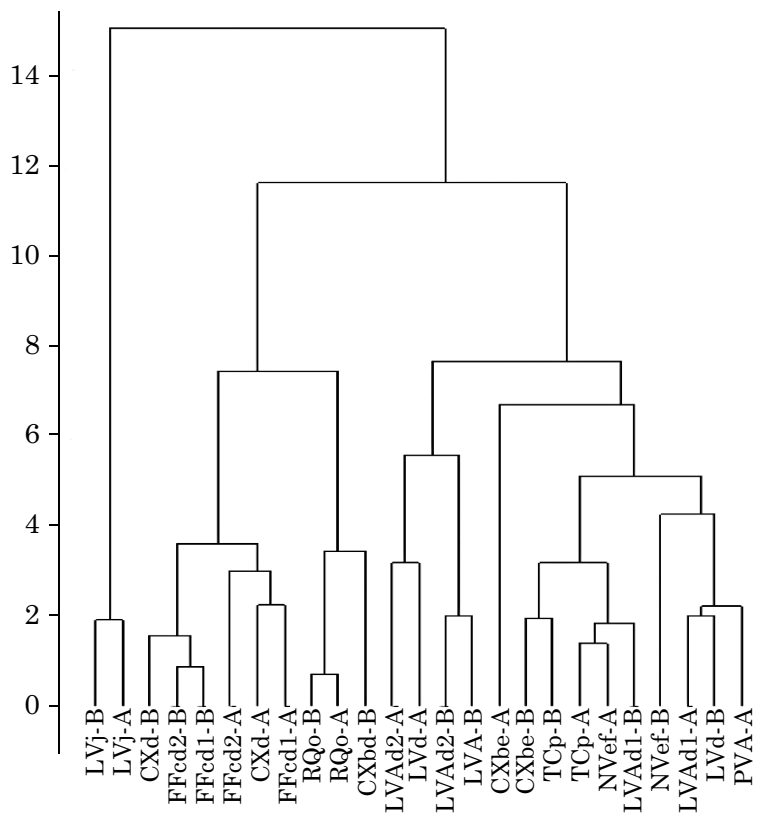

(b)

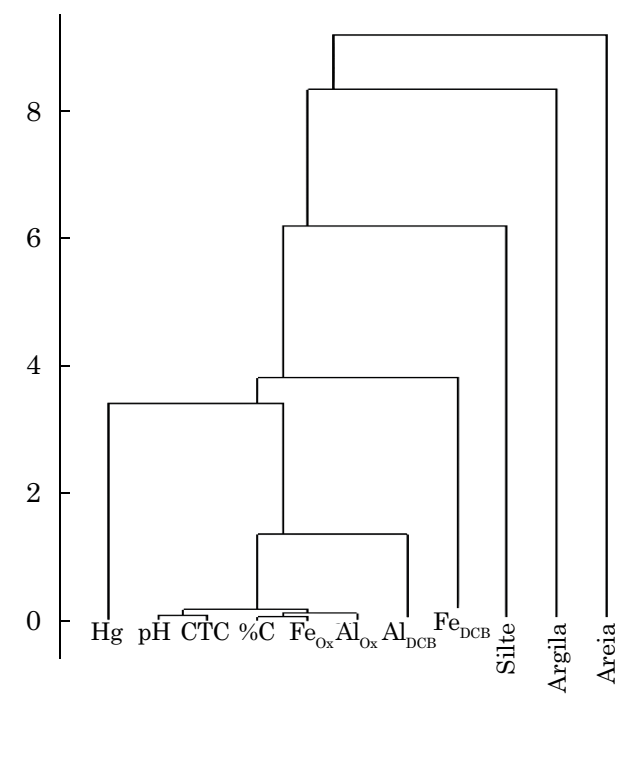

Figura 5. Dendogramas das (a) amostras e (b) variáveis obtidos por HCA para os dados escalados, empregando-se o método de Ward e distância de Mahalanobis.

não significa que a interação entre a matéria orgânica e o Hg seja fraca ou pouco expressiva, visto que a ligação do $\mathrm{Hg}$ com a matéria orgânica é controlada por pequena fração de moléculas que apresentam grupos funcionais contendo enxofre. A retenção do $\mathrm{Hg}$ é determinada, portanto, pelo tipo de matéria orgânica e não simplesmente pelo teor da mesma.

Das 22 amostras que constituíam horizontes A e B de 11 classes de solos, houve diferença significativa entre os teores de $\mathrm{Hg}$ dos horizontes A e B para cinco solos: NVef, CXbe, LVj, FFcd ${ }_{2}$ e RQo. Entre esses, o teor de $\mathrm{Hg}$ foi maior no horizonte $\mathrm{B}$ do que no A, exceto para o solo NVef. Segundo Roulet et al. (1998), o Hg pode se acumular no horizonte B dos solos por se associar com óxidos de $\mathrm{Fe}$. $\mathrm{O} \mathrm{Hg}$ pode ser adsorvido na superfície mineral, complexado por goethita, adsorvido em óxidos de Fe ou copecipitado (Roulet e Lucotte, 1995).

No entanto, entre esses solos, os teores de óxidos de $\mathrm{Fe}$ dos horizontes $\mathrm{B}$ não são expressivamente superiores aos dos horizontes A. A exceção ocorre para o solo NVef, onde o teor de óxidos de Fe do horizonte $\mathrm{B}$ é o dobro do teor de óxidos de Fe do horizonte A; e, justamente para o solo NVef, o teor de $\mathrm{Hg}$ no horizonte A é maior que no horizonte B. $\mathrm{O}$ horizonte A do solo NVef apresentou maior $\mathrm{pH}$ e maior porcentagem de $\mathrm{C}$, enquanto o horizonte $\mathrm{B}$ apresentou maior teor de argila, maior CTC e maiores teores de óxidos de Fe e Al. Portanto, para o solo NVef, o $\mathrm{pH}$ e a matéria orgânica parecem ser os principais fatores que atuam na retenção do Hg. Segundo Roulet e Lucotte (1995), esse comportamento é compreensível visto que o $\mathrm{Hg}$ apresenta maior afinidade por substâncias húmicas do que por íons inorgânicos como cloreto e hidroxila. Novamente, a falta de correlação entre teor de $\mathrm{Hg}$ e porcentagem de $\mathrm{C}$ se justifica pelo fato de a retenção de $\mathrm{Hg}$ ser determinada pelo tipo de matéria orgânica e não simplesmente pelo seu teor. É provável que nesse solo a matéria orgânica tenha carga dependente do $\mathrm{pH}$; logo, o alto $\mathrm{pH}$, além de promover a retenção do $\mathrm{Hg}$ por precipitação, favorece a formação de complexos de esfera interna com os grupamentos desprotonados da matéria orgânica.

Considerando-se apenas os solos NVef, CXbe, $\mathrm{LVj}, \mathrm{FFcd}_{2}$ e RQo, que apresentaram diferença significativa entre os teores de $\mathrm{Hg}$ dos horizontes A e $\mathrm{B}$, o teor de $\mathrm{Hg}$ apresenta correlação significativa com o pH $(\mathrm{r}=0,81)$, a CTC $(\mathrm{r}=0,73)$ e o teor de argila $(r=0,96)$. Uma vez que para esse grupo de solos existe uma correlação significativa entre a porcentagem de $\mathrm{C}$ e a CTC $(r=0,72)$, que não apareceu para nenhum grupo de amostras citado anteriormente no texto, pode-se inferir que, nesses solos, o $\mathrm{Hg}$ deve estar retido pelas cargas negativas, sem afinidade específica com nenhuma fase mineral ou orgânica; dessa forma, a natureza das argilas e a da matéria orgânica, associadas aos teores desses dois constituintes, se complementam no sentido de fornecer os sítios de adsorção eletrostática para a retenção do Hg. Novamente, verificou-se que a porcentagem de C não apresentou correlação com o teor de $\mathrm{Hg}$ do solo. 
Em relação ao grupo de amostras que apresentaram teor de $\mathrm{Hg}$ superior a $50 \mu \mathrm{g} \mathrm{kg}^{-1}$, observou-se que o teor de $\mathrm{Hg}$ evidenciou correlação positiva significativa apenas com o $\mathrm{pH}(\mathrm{r}=0,77)$ e com a CTC $(r=0,63)$. Novamente, obteve-se correlação positiva significativa entre o teor de $\mathrm{Hg}$ e o $\mathrm{pH}$. Como as amostras com teores mais altos de $\mathrm{Hg}$ são todas argilosas, a textura não foi capaz de diferenciá-las. Nesse caso, a CTC passa a ser fator importante, amostras com maior CTC demonstraram teores mais altos de Hg. Esses resultados sugeriram que nesse grupo de amostras é bem provável que o Hg já tenha sido liberado pelo intemperismo dos minerais primários e seja retido por equilíbrios de adsorção, seja eletrostática ou quimissorção.

Tanto para o grupo de solos NVef, CXbe, $\mathrm{LVj}, \mathrm{FFcd}_{2}$ e RQo, que apresentaram diferença significativa entre os teores de $\mathrm{Hg}$ dos horizontes $\mathrm{A} \mathrm{e} \mathrm{B}$, quanto para o grupo de solos com teor total de $\mathrm{Hg}$ superior a $50 \mu \mathrm{g} \mathrm{kg}{ }^{-1}$, verificou-se correlação significativa entre o teor de Hg e a CTC. Tal correlação não apareceu para o grupo de todas as amostras. Como o $\mathrm{pH}$ influencia na CTC, para esses solos a correlação entre o teor de $\mathrm{Hg}$ e a CTC tem grande influência da correlação entre $\mathrm{pH}$ e teor de $\mathrm{Hg}$. Maiores valores de $\mathrm{pH}$ e CTC contribuem para o aumento de disponibilidade de sítios aniônicos para a adsorção de $\mathrm{Hg}$.

\section{CONCLUSÕES}

Os solos estudados apresentaram teores de mercúrio abaixo do limite de prevenção de $500 \mu \mathrm{g} \mathrm{kg}^{-1}$ estabelecido pelo COPAM, com média de $81 \mu \mathrm{g} \mathrm{kg}^{-1}$ e máximo de $215 \mu \mathrm{g} \mathrm{kg}^{-1} ; 48 \%$ dos solos estudados evidenciaram teor de mercúrio inferior ao VRQ $\left(50 \mu \mathrm{g} \mathrm{kg}^{-1}\right)$.

$\mathrm{O} \mathrm{pH}$ e teor de argila foram as características mais importantes para a concentração de mercúrio nos solos e, secundariamente, a CTC.

Não houve correlação significativa entre o teor de mercúrio e a porcentagem de carbono, o que demonstrou que foi inviável comparar quantitativamente matérias orgânicas distintas quanto à retenção de mercúrio.

A maioria dos solos demonstrou maior teor de mercúrio no horizonte $\mathrm{B}$ do que no $\mathrm{A}$.

Para as amostras com teores mais altos de mercúrio, a textura não foi capaz de diferenciá-las, sendo o pH e a CTC os fatores importantes.

\section{AGRADECIMENTOS}

Ao CNPq e à FAPEMIG (Projeto CRA-APQ03861-09), pelos recursos financeiros.

\section{REFERÊNCIAS}

Agostino FD, Oliveri E, Bagnato E, Falco F, Mazzola S, Sprovieri M. Direct determination of total mercury in phosphate rock using alkaline fusion digestion. Anal Chim Acta. 2014;852:8-12.

Biester H, Muller G, Scholer HF. Binding and mobility of mercury in soils contaminated by emissions from chlor-alkali plants. Sci Total Environ. 2002;284:191-203.

Brown GE, Parks GA, O’Day PA. Sorption at mineral-water interfaces: Macroscopic and microscopic perspectives. In: Vaughan DJ, Pattrick RAD, editors. Mineral surfaces. London: Chapman \& Hall; 1995. p.129-83.

Cabral AR, Rocha Filho OG, Jones RD. Mercury in itabirite-hosted soft hematite ore in the Quadrilátero Ferrífero of Minas Gerais. J Geochem Explor. 2008;96:69-76.

Cesar R, Egler S, Polivanov H, Castilhos Z, Rodrigues AP. Mercury, copper and zinc contamination in soils and fluvial sediments from an abandoned gold mining area in southern Minas Gerais State, Brazil. Environ Earth Sci. 2011;64:211-22.

Chen Xi, Xia X, Wu S, Wang F, Guo X. Mercury in urban soils with various types of land use in Beijing, China. Environ Pollut. 2010;158:48-54.

Claessen MEC, organizador. Manual de métodos de análise de solo. $2^{\text {a }}$.ed. Rio de Janeiro: Embrapa-CNPS; 1997.

Conselho Estadual de Política Ambiental - COPAM. Altera o Anexo I da Deliberação Normativa Conjunta COPAM CERH $\mathrm{n}^{\circ} 2$ de 6 de setembro de 2010, estabelecendo os Valores de Referência de Qualidade dos Solos. Deliberação Normativa n ${ }^{\circ} 166$, de 29 de junho de 2011. Diário do Executivo - "Minas Gerais", 27 jul. de 2011.

Departamento Nacional de Produção Mineral - DNPM. Anuário Mineral Brasileiro 2010. Brasília: 2010. [Acessado em: 22 maio 2014]. Disponível em: http://www.dnpm.gov.br/relatorios/amb/ Completo_2010.pdf.

Ericksen JA, Gustin MS, Xin M, Weisberg PJ, Fernandez GCJ. Air-soil exchange of mercury from background soils in the United States. Sci Total Environ. 2006;366:851-63.

Fergusson JE. The heavy elements. Chemistry, environmental impacts and health effects. New York: Pergamon Press; 1990.

García-Sánchez A, Murciego A, Álvarez-Ayuso E, Santa Regina I, Rodríguez-González MA. Mercury in soils and plants in an abandoned cinnabar mining area (SW Spain). J Hazard Mater. 2009;68:1319-24.

González-Fernández B, Menéndez-Casares E, Meléndez-Asensio M, Fernández-Menéndez S. Sources of mercury in groundwater and soils of west Gijón (Asturias, NW Spain). Sci Total Environ. 2014;481:217-31.

Gosar M, Sajn R, Biester H. Binding of mercury in soils and attic dust in the Idrija mercury mine area (Slovenia). Sci Total Environ. 2006;369:150-62.

Grangeon S, Guédron S, Asta J, Sarret G, Charlet L. Lichen and soil as indicators of an atmospheric mercury contamination in the vicinity of a chlor-alkali plant (Grenoble, France). Ecol Indic. 2012;13:178-83.

Grimaldi C, Grimaldi M, Guedron S. Mercury distribution in tropical soil profiles related to origin of mercury and soil processes. Sci Total Environ. 2008;401:121-9. 
Guédron S, Grangeon S, Jouravel G, Charlet L, Sarret G. Atmospheric mercury incorporation in soils of an area impacted by a chlor-alkali plant (Grenoble, France): Contribution of canopy uptake. Sci Total Environ. 2013;445/446:356-64.

Hall GEM, Pelchat P. Evaluation of a direct solid sampling atomic absorption spectrometer for the trace determination of mercury in geological samples. Analyst. 1997;122:921-4.

Hissler C, Probst JL. Impact of mercury atmospheric deposition on soils and streams in a mountainous catchment (Vosges, France) polluted by chlor-alkali industrial activity: the important trapping role of the organic matter. Sci Total Environ. 2006;361:163-78.

Jackson ML. Soil chemical analysis. Englewood Cliffs: Prentice-Hall; 1958.

Lechler PJU, Miller JR, Lacerda LD, Vinson D, Bonzongo JC, Lyons WB, Warwick JJ. Elevated mercury concentrations in soils, sediments, water, and fish of the Madeira River basin, Brazilian Amazon: A function of natural enrichments? Sci Total Environ. 2000;260:87-96.

Malferrari D, Brigatti MF, Elmi C, Laurora A. Determination of $\mathrm{Hg}$ binding forms in contaminated soils and sediments: state of the art and a case study approaching abandoned mercury mines from Mt. Amiata (Siena, Italy). J Mineral Geochem. 2011;188:65-74.

Mcbride MB. Environmental chemistry of soils. New York: Oxford University Press; 1994.

Mckeague JA, Day JH. Dithionite and oxalate-extractable Fe and $\mathrm{Al}$ as aids in differentiating various classes of soil. Can $\mathrm{J}$ Soil Sci. 1966;46:13-22.

Mcneal JM, Rose AW. The geochemistry of mercury in sedimentary rocks and soils in Pennsylvania. Geochim Cosmochim Acta. 1974;38:1759-84.

Mehra OP, Jackson ML. Iron oxide removal from soils and clays by a dithionite-citrate system buffered with sodium bicarbonate. Clays Clay Min. 1960;7:317-27.

Mello JWV, Abrahão WAP. Solos contaminados no Brasil. O desafio de definir valores de referência. Bol Inf SBCS. 2013;38:12-7.

Miller JC, Miller JN. Estadística para química analítica. $2^{\text {a }}$.ed. Wilmington: Addison-Wesley Iberoamerican; 1993.

Palmieri HEL, Nalini Jr, HA, Leonel LV, Windmoller CC, Santos RC, Brito W. Quantification and speciation of mercury in soils from the Tripuí Ecological Station, Minas Gerais, Brazil. Sci Total Environ. 2006;368:69-78.

Pérez-Sirvent C, Martínez-Sánchez MJ, García-Lorenzo ML, Molina J, Tudela ML. Geochemical background levels of zinc, cadmium and mercury in anthropically influenced soils located in a semi-arid zone (SE, Spain). Geoderma. 2009;148:307-17.

Ravichandran M. Interactions between mercury and dissolved organic matter - a review. Chemosphere. 2004;55:319-51.
Resende M, Curi N, Ker JC, Rezende SB. Mineralogia de solos brasileiros: Interpretação e aplicações. Lavras: Universidade Federal de Lavras, 2005.

Roulet M, Lucotte M. Geochemistry of mercury in pristine and flooded ferralitic soil of a tropical rain forest in French Guiana, South America. Water Air Soil Pollut. 1995;80:1079-88.

Roulet M, Lucotte M, Saint-Aubin A, Tran S, Rheault I, Farella N, Silva ED, Dezencourt J, Passos CJS, Soares GS, Guimaraes JRD, Mergler D, Amorim M. The geochemistry of mercury in central Amazonian soils developed on the Alter-do-Chão formation of the lower Tapajós River Valley, Pará state, Brazil. Sci Total Environ. 1998;223:1-24.

Santos HG, Jacomine PKT, Anjos LHC, Oliveira VA, Oliveira JB, Coelho MR, Lumbreras JF, Cunha TJF, editores. Sistema brasileiro de classificação de solos. Rio de Janeiro: Embrapa Solos; 2006.

Srivastava RK. The abundance of mercury in rocks, minerals and native sulphur by a microwave-excited argon plasma. Chem Geol. 1979;27:255-63.

Swenson JJ, Carter CE, Domec JC, Delgado CI. Gold Mining in the Peruvian Amazon: Global prices, deforestation, and mercury imports. PlosOne. 6, 2011. doi:10.1371/journal. pone.0018875.

Sposito G. The chemistry of soils. New York: Oxford University Press; 2008.

Tack F, Vanhaesebroeck T, Verloo MG, van Rompaey K, van Ranst E. Mercury baseline levels in Flemish soils (Belgium). Environ Pollut. 2005;134:173-9.

UNEP Chemicals Branch. The global atmospheric mercury assessment: Sources, emissions and transport. Geneva: UNEP-Chemicals; 2008.

Valle CM, Augusti R, Santana GP, Egreja Filho FB, Windmöller CC. Speciation and quantification of mercury in Oxisol, Ultisol and Spodosol from Amazon (Manaus, Brazil). Chemosphere. 2005;58:779-92.

Varejão EVV, Bellato CR, Fontes MPF. Mercury fractionation in stream sediments from the Quadrilátero Ferrífero gold mining region, Minas Gerais State, Brazil. Environ Monit Assess. 2009;157:125-35.

Wang D, Shi X, Wei S. Accumulation and transformation of atmospheric mercury in soil. Sci Total Environ. 2003;304:209-14.

Wasserman JC, Campos RC, Hacon SS, Farias RA, Caires SM. Mercury in soils and sediments from gold mining liabilities in southern Amazonia. Quim Nova. 2007;30:768-73.

Windmoller CC, Santos RC, Athayde M, Palmieri HEL. Distribuição e especiação de mercúrio em sedimentos de áreas de garimpo de ouro do quadrilátero ferrífero (MG). Quim Nova. 2007;30:1088-94. 